\title{
Reflets
}

Revue ontaroise d'intervention sociale et communautaire

\section{La Marche mondiale des femmes en l'an 2000 en Ontario français}

\section{Marie-Hélène Gérome}

Volume 6, numéro 1, printemps 2000

Approches d'intervention : définir et renouveler nos pratiques

URI : https://id.erudit.org/iderudit/026302ar

DOI : https://doi.org/10.7202/026302ar

Aller au sommaire du numéro

Éditeur(s)

Reflets : Revue ontaroise d'intervention sociale et communautaire

ISSN

1203-4576 (imprimé)

1712-8498 (numérique)

Découvrir la revue

Citer cet article

Gérome, M.-H. (2000). La Marche mondiale des femmes en l'an 2000 en Ontario français. Reflets, 6(1), 192-196. https://doi.org/10.7202/026302ar

Tous droits réservés (C) Reflets : Revue ontaroise d'intervention sociale et communautaire, 2000
Ce document est protégé par la loi sur le droit d'auteur. L'utilisation des services d'Érudit (y compris la reproduction) est assujettie à sa politique d'utilisation que vous pouvez consulter en ligne.

https://apropos.erudit.org/fr/usagers/politique-dutilisation/ 


\title{
La Marche mondiale des femmes en l'an 2000 en Ontario français
}

\author{
Marie-Hélène Gérome, \\ Table féministe francophone de concertation provinciale de l'Ontario
}

\section{Une Marche des femmes tous azimuts!}

Le 8 mars a marqué le lancement de la Marche mondiale des femmes de l'an 2000 qui mobilisera les femmes aux niveaux local, national et international, à travers 143 pays. Si le 8 mars, Journée internationale des femmes, peut ordinairement être l'occasion de célébrer les acquis des femmes, à l'aube de ce nouveau millénaire, les femmes font carrément volte-face et s'unissent pour dénoncer les politiques discriminatoires instaurées par les gouvernements, à l'heure de la mondialisation.

La Marche mondiale des femmes en l'an 2000 fait suite à la Marche du Pain et des roses, organisée en 1995 par les femmes du Québec. Celle-ci avait comme objectif d'inciter le gouvernement québécois à adopter des mesures concrètes pour mettre fin à l'appauvrissement des femmes. Cette année, la Marche mondiale poursuit un dessein similaire en interpellant nos gouvernements, les Nations Unies et les grandes institutions telles que le Fond monétaire international et la Banque Mondiale, afin qu'ils mettent un terme à la pauvreté et à la violence faite aux femmes et ce, sans condition aucune. De surcroit, la Marche mondiale transmet à ces mêmes instances deux revendications portant sur les droits des lesbiennes, afin que l'orientation sexuelle ne prive personne du plein exercice des droits reconnus dans plusieurs instruments internationaux. 


\section{La mobilisation des femmes de l'Ontario français}

La Table féministe francophone de concertation provinciale de l'Ontario (TFFCPO), en partenariat avec Action ontarienne contre la violence faite aux femmes (AOcVF), ont le mandat de représenter les femmes francophones ou d'expression française de la province dans le cadre de la Marche mondiale des femmes en l'an 2000. Ces organismes veulent profiter de cet événement pour mener une campagne permanente de sensibilisation auprès des femmes.

Ainsi, en premier lieu, cette campagne de sensibilisation donnera une voix aux femmes de l'Ontario français et assurera leur visibilité face aux défis qu'elles rencontrent, à l'heure où le gouvernement provincial applique la ligne dure et fait fi de l'intérêt public! En second lieu, cette même campagne cherche à promouvoir la participation des femmes à la vie politique en les impliquant et en espérant que cela suscite chez elles le désir d'être plus présentes dans tous les espaces où se prennent les décisions qui ont un impact sur leur vie et sur celle de leurs enfants.

J'entends déjà le commentaire : «c'est complètement irréaliste?». Nullement, car si nous regardons l'histoire, nous savons pertinemment que ce n'est pas la première fois que les femmes se mobilisent en vue d'inciter les gouvernements à réviser leur manière d'agir. En emboîtant le pas aux groupes qui les ont précédés, les femmes jugent incontournable et impératif de reprendre le flambeau en développant diverses stratégies et différentes activités afin de faire entendre leur voix auprès des gouvernements. Et la Marche mondiale des femmes en l'an 2000 sert à cette fin.

\section{Notre plan d'action}

Au préalable, il est important de préciser que les différentes activités, faites ou prévues par la TFFCPO et l'AOcVF depuis le 8 mars 2000, atteindront leur point culminant lors du grand 
Rassemblement des femmes de l'Ontario français qui aura lieu les 13 et 14 octobre 2000, à Ottawa.

\section{Des ateliers d'éducation populaire}

Des feuillets sur la pauvreté, la violence faite aux femmes et les droits des lesbiennes, produits par la TFFCPO et l'AOcVF, servent d'outils de sensibilisation dans le cadre d'ateliers d'éducation populaire et permettent de poursuivre plusieurs objectifs :

- sensibiliser les femmes aux enjeux qui les concernent et mieux comprendre comment les actions des gouvernements sont menées de manière telle que les femmes se retrouvent dans des situations où elles ne possèdent aucun pouvoir;

- outiller les femmes pour qu'elles soient en mesure d'interpeller les gouvernements et les inciter à poser des actions concrètes en vue d'éliminer la pauvreté et la violence faite aux femmes et les forcer à respecter leurs engagements contractés lors de la signature de traités, de conventions et de pactes internationaux afin que les droits humains soient toujours pris en considération;

- inviter les femmes à faire des revendications, à faire entendre leur voix et à proposer des solutions alternatives susceptibles d'avoir un impact sur leur vie quotidienne et sur la société dans son ensemble.

\section{Le projet d'une courtepointe}

Une courtepointe sera confectionnée et sera composée de plusieurs carrés de tissus sur lesquels les femmes sont invitées à inscrire une revendication. Tout en étant une œuvre collective, la courtepointe se veut un outil de revendication qui servira de toile de fond lors des grandes manifestations à Queen's Park ou lors du Rassemblement des femmes de l'Ontario français en octobre 2000, et possiblement à New York, à l'occasion du rassemblement mondial des femmes. L'Union culturelle des franco-ontariennes et la Fédération des femmes canadiennesfrançaises de l'Ontario sont chargées de mener à bien ce projet. 


\section{La campagne de signatures}

Des cartes-réponses, comportant à la fois le logo de la Marche mondiale des femmes en l'an 2000 et le slogan proposé par les femmes de l'Ontario français «Pour la liberté et la sécurité de toutes les femmes du monde!», seront distribuées dans les groupes de femmes, dans les écoles et les centres communautaires. Une fois signées, ces cartes seront envoyées à son Excellence Kofi Annan, Secrétaire Général des Nations Unies, avant le 17 octobre 2000.

\section{Le Manifeste des femmes de l'Ontario français}

Les revendications émises par les femmes lors des ateliers d'éducation populaire ou qui seront inscrites sur les carrés de tissus de la courtepointe, feront l'objet d'un Manifeste des femmes de l'Ontario français. Ce manifeste sera entériné lors du Rassemblement des femmes de l'Ontario français le 13 et 14 octobre 2000. Il sera ensuite présenté à Queen's Park en décembre 2000, afin d'inciter les gouvernements à corriger leurs politiques pour répondre de manière adéquate aux besoins des femmes tout en respectant leur diversité.

\section{Le Rassemblement des femmes de l'Ontario français}

En Ontario français, les journées du 13 et du 14 octobre 2000 seront le point culminant de la Marche mondiale des femmes en l'an 2000. En plus de permettre l'adoption des revendications qui composeront le Manifeste des femmes de l'Ontario français, ces journées seront l'occasion pour partager des informations afin d'explorer des solutions alternatives susceptibles de mettre un terme à la pauvreté et à la violence faite aux femmes. Ce temps fort permettra aussi de réfléchir à l'après marche et au suivi à donner à toutes les stratégies qui auront été élaborées par les femmes de l'Ontario français, dans le cadre de la Marche mondiale des femmes en l'an 2000.

D'autres activités sont prévues dans les divers coins de l'Ontario français. Au sein de chaque région, les femmes francophones ou d'expression française témoignent de leur créativité et déploient 
toutes leurs énergies pour permettre aux femmes de la province d'unir leur voix à celle des femmes du monde entier, nourries par l'espoir de créer un monde empreint d'une plus grande justice sociale et de plus d'égalité. 